\title{
Spectrum of pediatric heart disease in newly established cardiac center in South Punjab.
}

1. FCPS (Paediatric Medicine), FCPS (Paediatric Cardiology) Professor Paediatric Cardiology Quaid-e-Azam Medical College Bahawalpur.

2. FCPS Paediatric Medicine Assistant Professor Paediatric Medicine

Quaid-e-Azam Medical College Bahawalpur.

3. FCPS (Paediatric Medicine), FCPS (Paediatric Cardiology) Assistant Professor Paediatric Cardiology

Faisalabad Institute of Cardiology Faisalabad

Correspondence Address: Dr. Ahsan Beg

Department of Pediatric Cardiology Cardiac Centre, Quaid-e-Azam Medical College Bahawalpur. dr.ahsan.beg@hotmail.com

Article received on: 30/07/2020

Accepted for publication: $10 / 09 / 2020$

\begin{abstract}
Ahsan Beg', Nousheen Fatima ${ }^{2}$, Abdul Razzaq Mughal ${ }^{3}$
ABSTRACT... Objectives: To determine the spectrum of pediatric heart disease in a newly established cardiac centre in South Punjab. Study Design: Descriptive observational case series. Setting: Department of Pediatric Cardiology of Cardiac Center Bahawal Victoria Hospital (BVH) Bahawalpur. Period: Six months from July 2019 to December 2019. Material \& Methods: All consecutive patients of any gender, age range from first day of life to 18 years, diagnosed as having heart disease (congenital/ acquired) on echocardiography were enrolled. Patients of isolated bicuspid aortic valve, premature neonates having PDA or those who already had balloon, device or surgical intervention done for congenital heart disease were excluded from the study. The spectrum of heart diseases in children was assessed by categorizing them as having acquired, acyanotic and cyanotic heart defects. Results: A total of 624 patients were enrolled in the study on the basis of inclusion criteria. There were $56.7 \%$ male $(n=354)$ and $43.3 \%$ female $(n=270)$ with male to female ratio 1.3:1. Majority of the patients were of infant age group $(66 \%, n=412)$. Congenital heart disease (CHD) was present in $87 \%$ of the patients $(n=543)$ while $13 \%(n=81)$ had acquired heart disease (AHD). Acyanotic heart lesions were found in $73.1 \%$ of patients while cyanotic congenital heart diseases (CCHD) were $26.9 \%$. Ventricular septal defect was the most common CHD (33\%) followed by atrial septal defect (14.9\%) and patent ductus arteriosus (13.1\%). Tetralogy of Fallot was the most common CCHD (10.1\%) followed by transposition of great arteries (7.4\%). Among AHD, 55.6\% were of rheumatic heart disease followed by cardiomyopathy (27.2), pericardial effusion (8.6\%) and infective endocarditis (4.9\%). Conclusion: The VSD, ASD, PDA, TOF and TGA remain the most common CHD in descending order while RHD is the most common acquired heart disease in children at our centre.
\end{abstract}

Key words: $\quad$ Acquired Heart Disease, Congenital Heart Disease, Rheumatic Heart Disease, Ventricular Septal Defect.

Article Citation: Beg A, Fatima N, Mughal AR. Spectrum of pediatric heart disease in newly established cardiac center in South Punjab. Professional Med J 2020; 27(11):2368-2375. https://doi.org/10.29309/TPMJ/2020.27.11.5866

\section{INTRODUCTION}

Heart diseases are the most important cause of morbidity and mortality in pediatric population. These include both the congenital as well as acquired heart diseases. Congenital heart disease (CHD) is defined as "a gross structural abnormality of the heart or intra thoracic great vessels that is actually or potentially of functional significance". ${ }^{1}$ It is the most common congenital anomaly in neonatal life. Global incidence of CHD is 8-12 per1000 live births. ${ }^{2}$ In a developing resource limited country like Pakistan the actual prevalence is not known as most of the child births still take place at home and no newborn screening strategy exist. Some studies have been done at local level to assess its prevalence. ${ }^{3,4}$
Annually almost 40,000 children are born with CHD. ${ }^{5}$

There is a vast range of congenital heart defects including ventricular septal defect (VSD), atrial septal defect (ASD), atrioventricular septal defect (AVSD), patent ductus arteriosus (PDA), tetralogy of Fallot (TOF), transposition of great arteries (TGA), tricuspid atresia and many more. These defects may be isolated or in combination and may also involve valves of the heart. The congenital heart disease spectrum includes both acyanotic as well as cyanotic heart defects. The clinical presentation of CHD is variable. Patients may be completely asymptotic or may present with feeding difficulty, fatigue, poor growth, and 
cyanosis or with congestive cardiac failure. ${ }^{6}$ The children suffering from heart disease if not diagnosed timely may result in significant disability and mortality.

The acquired heart diseases (AHD) are the conditions affecting heart and its vessels during childhood. The AHD may involve pericardium, myocardium, valves and combination of all. It includes rheumatic heart disease, myocarditis, pericarditis, infective endocarditis and cardiomyopathy. ${ }^{3}$ Pakistan is an endemic country for rheumatic heart diseases. ${ }^{7}$ Echocardiography is the basic diagnostic tool in all the pediatric heart diseases. The cardiac centre of Bahawal Victoria Hospital (BVH) Bahawalpur serves a large area of population, with poor accessibility to big cities, for treatment of heart diseases. The cardiac center includes the first ever pediatric cardiac care facility in this particular region. This study aims to determine the spectrum of heart disease in pediatric population in a newly established pediatric cardiology department of cardiac center in South Punjab so that a strategy may be devised for appropriate and timely treatment.

\section{MATERIAL \& METHODS}

It was a descriptive observational case series conducted at the pediatric cardiology department of cardiac center BVH Bahawalpur from July 1, 2019 to December 31, 2019. Approval of the study from ethics committee of the hospital was taken and there was no conflict of interest. All consecutive patients of any gender (male/ female/ transgender) and of age range from first day of life to18 years of life, who were diagnosed as confirmed cases of heart disease (congenital/ acquired) on echocardiography done by dedicated pediatric cardiologist of the hospital were enrolled for the study. The patients who had isolated arrhythmia without any structural heart defect, isolated bicuspid aortic valve with normal function or premature neonates having isolated PDA diagnosed in the first 3 months of life were excluded from the study. Similarly those patients who already had cured their heart disease by surgery or device intervention or had a palliative balloon are surgical procedure were also excluded from the study. The demographic and clinical details were taken from patients visiting out patient department (OPD) as well as from admitted patients including history, clinical examination, age, gender and definite diagnosis of heart disease (congenital/acquired). The cardiac diagnosis based on echocardiography was reviewed in the entire study subjects and where more than one structural abnormality was present, the leading or main diagnosis was chosen. The spectrum of the heart diseases in children was assessed by categorizing them as having acquired heart disease, acyanotic CHD and cyanotic CHD.

Informed consent was taken from the parents and confidentiality of personal data of the patient was assured to them by the principal investigator in a comfortable environment. All the data was entered on an investigator designed Proforma and then shifted to excel sheet and analyzed. The descriptive analysis for spectrum of pediatric heart defects was done by sorting out frequencies and percentages of qualitative variables like congenital heart defects (cyanotic/acyanotic) as well as acquired heart defects.

\section{RESULTS}

A total of six hundred and twenty four patients were enrolled in the study on the basis of inclusion criteria. Out of these subjects with heart disease $56.7 \%$ were male $(n=354)$ and $43.3 \%$ female $(n=270)$ with male to female ratio 1.3:1. Majority of the children presented in OPD of the hospital $(n=560,89.7 \%)$. As regard age of the patients we divided the study subjects in five different groups and majority of the patients were of infant age group $(66 \%, n=412)$. Congenital heart disease was present in $87 \%$ of the patients $(n=543)$ while $13 \%(n=81)$ had acquired heart disease. In congenital heart diseases, acyanotic heart lesions were found in $73.1 \%$ of patients while cyanotic heart diseases (CCHD) were $26.9 \%$. Male patients were more affected with congenital heart diseases (65\%) while female dominated the acquired heart diseases $(n=44)$.

Table-I shows the base line characteristics of patients including age, gender and heart disease distribution in patients. 


\begin{tabular}{|l|c|}
\hline \multicolumn{1}{|c|}{ Baseline Characteristics } & No. (\%) \\
\hline Gender & \\
Male & $354(56.7)$ \\
Female & $270(43.3)$ \\
Mode of presentation & \\
OPD visit & $560(89.7)$ \\
Indoor admission & $64(10.3)$ \\
Age Distribution & \\
1 to 30 Days & $150(24)$ \\
1 Month to 1 Year & $262(42)$ \\
1-5 Years & $72(11.5)$ \\
5-12 Years & $109(17.5)$ \\
12-18 Years & $31(5)$ \\
Types of Heart Diseases & \\
Congenital heart disease & $543(87)$ \\
Acquired heart disease & $81(13)$ \\
Distribution of CHD & \\
Acyanotic & $397(73.1)$ \\
Cyanotic & $146(26.9)$ \\
$\quad \quad$ Table-I. Base line characteristics. \\
\hline \multicolumn{2}{l}{}
\end{tabular}

\section{Congenital Heart Diseases}

We further analyzed the frequency and spectrum of congenital heart diseases with special reference to acyanotic and cyanotic CHD variety. The most common congenital heart defects were acyanotic lesions like VSD, ASD and PDA followed by cyanotic lesions like TOF and TGA. Ventricular septal defect was the most common $\mathrm{CHD}(\mathrm{n}=179,33 \%)$ as a whole and in acyanotic group too. As regard size of the VSD, $45 \%$ were of large size, $11 \%$ of moderate to large size, $25 \%$ of moderate size and $19 \%$ were of small size. Atrial septal defect was the second most common lesion in CHD (14.9\%) followed by patent ductus arteriosus seen in 71 patients (13.1\%). Table-II shows frequency of acyanotic congenital heart diseases.

Tetralogy of Fallot (TOF) was the most common cyanotic CHD and fourth in order of frequency among congenital heart defects (10.1\%). Majority were typical TOF $(67 \%)$ having right to left shunt at ventricular level, $25 \%$ had bidirectional shunt while $8 \%$ were not apparently blue, had typical TOF like anatomy but left to right shunt at ventricular level. Transposition of great arteries (TGA) was the fifth most common congenital heart defect $(7.4 \%)$ but second common among cyanotic lesions. TableII shows the frequency of cyanotic heart defects.

\section{Acquired Heart Diseases}

The acquired heart diseases were present in only $13 \%$ of patients $(n=81)$. Most of these patients were of age 5 to 12 years (63\%, $n=51), 16 \%$ above 12 years $(n=13)$ and $21 \%$ below five years of age $(n=17)$. The acquired heart diseases involved myocardium, pericardium, endocardium or all layers of the heart in combination. Rheumatic heart disease was seen in $55.6 \%$ of acquired heart defects. In rheumatic heart defects mitral valve was most frequently affected as $30 \%$ had mitral regurgitation (MR) alone, $51 \%$ had both mitral and aortic regurgitation (AR) and in 5\% tricuspid regurgitation accompanied MR, while $5 \%$ had mixed mitral valve disease. Isolated mitral valve stenosis (MS) was seen in $3 \%$ and isolated AR in $7 \%$ of the acquired heart disease patients.

Dilated cardiomyopathy (DCMP) was seen in $27.2 \%$ of patients $(n=22)$ while infective endocarditis was presents in 4 patients (4.9\%). Table-III shows the frequency and percentages of all the acquired heart defects mentioned above and other defects like pericardial effusion, acute pericarditis and hypertrophic cardiomyopathy.

As regard pulmonary hypertension it was present in 137 patients (22\%) out of all the study subjects $(n=624)$. Majority of patients were of CHD $(89.8 \%$, $n=123$ ) while $10.2 \%$ of patients were of acquired heart disease. As regard pulmonary hypertension in congenital hart disease patients, it was mainly associated with acyanotic CHD $(n=119,97 \%)$.

\section{DISCUSSION}

With improvement in diagnostic facilities the heart diseases are occupying an important place in the pediatric diseases. ${ }^{8}$ Late presentation as well as late diagnosis of pediatric heart diseases in developing countries is due to illiteracy, poverty and limited resources. Early diagnosis of heart disease in children was a dilemma once here in Pakistan which is a developing country but with advancement of diagnostic facilities in different big cities and availability of more pediatric cardiologists in Pakistan it has become possible now to diagnose the cardiac problems at early life. 


\begin{tabular}{|l|c|l|c|}
\hline \multicolumn{1}{|c|}{ Acyanotic CHD } & $\begin{array}{c}\text { Number } \\
\text { (Percentage) }\end{array}$ & \multicolumn{1}{c|}{$\begin{array}{c}\text { Cyanotic CHD } \\
\text { (Percentage) }\end{array}$} \\
\hline Ventricular septal defect & $179(33)$ & Tetralogy of Fallot & $55(10.1)$ \\
\hline Atrial septal defect & $81(14.9)$ & Transposition of great arteries & 40 (7.4) \\
\hline Patent ductus arteriosus & $71(13.1)$ & Pulmonary atresia & 13.4) \\
\hline Atrioventricular septal defect & $22(4)$ & Total anomalous pulmonary venous connection & 11 (2) \\
\hline Pulmonary valve stenosis & $17(3.1)$ & Tricuspid atresia & (1.5) \\
\hline Valvular aortic stenosis & $12(2.2)$ & cc TGA & $7(1.3)$ \\
\hline Coarctation of aorta & $7(1.3)$ & Ebstein anomaly & $4(0.7)$ \\
\hline Mitral valve Prolapse & $4(0.7)$ & Univentricular Heart & $4(0.7)$ \\
\hline Sub-pulmonic obstruction & $2(0.4)$ & Truncus arteriosus & $3(0.6)$ \\
\hline Sub-aortic obstruction & $2(0.4)$ & Hypo-plastic left heart syndrome & $1(0.2)$ \\
\hline Total of above & $\mathbf{3 9 7 ( 7 3 . 1 )}$ & Total of above \\
\hline
\end{tabular}

\begin{tabular}{|l|c|}
\hline \multicolumn{1}{|c|}{$\begin{array}{c}\text { Type of Acquired Heart } \\
\text { Diseases }\end{array}$} & $\mathbf{n = 8 1 , ( \% )}$ \\
\hline Rheumatic heart disease & $45(55.6)$ \\
\hline Dilated cardiomyopathy & $22(27.2)$ \\
\hline Pericardial effusion & $7(8.6)$ \\
\hline Infective endocarditis & $4(4.9)$ \\
\hline Acute pericarditis & $2(2.5)$ \\
\hline Hypertrophic cardiomyopathy & $1(1.2)$ \\
\hline \multicolumn{2}{|c|}{ Table-III. Spectrum of acquired heart diseases. } \\
\hline \multicolumn{2}{|c|}{}
\end{tabular}

In our study the most common age group of congenital heart defects was infancy and it correlates well with the local studies $^{9}$ and developing countries data $^{10}$ but not with international data as most of their patients present and diagnosed in neonatal age group. ${ }^{11}$ As regard gender the congenital heart defects were more commonly seen in male as compared to female sex in our study. Most of the available studies also describe the male gender dominance while a few describe almost equal prevalence. ${ }^{12,13} \mathrm{~A}$ study conducted in Liaquat national hospital Karachi showed male to female ratio of $1.2: 1 .^{9}$ The male to female ratio in our study was 1.3:1 which is almost comparable to the Karachi study. We divided the discussion of pediatric heart disease spectrum in to congenital and acquired heart defects.

\section{Congenital Heart Defects}

Among congenital heart defects acyanotic heart defects were more prevalent than the cyanotic lesions. In our study the most common congenital heart lesions were VSD, ASD and PDA respectively and this data matches with the other available studies. ${ }^{14,15}$

A study conducted in Ibadan Nigeria ${ }^{16}$ described that over all incidence of VSD in children (isolated VSD as well as VSD with ASD and VSD with PDA) was $41.6 \%$. The study was conducted on little number of cases diagnosed by echocardiography. In our study the incidence of VSD was 33\% but we had a larger number of children of CHD as compared to above mentioned study. As regard VSD our study matches with some of old studies in Pakistan like Sadiq $\mathrm{M}$ et $\mathrm{al}^{3}$, Ahmad $\mathrm{R}$ et $\mathrm{al}^{17}$ and Rahim $\mathrm{F}$ et $\mathrm{al}^{18}$ where the incidence of VSD was $32.1 \%, 42.2 \%$ and $46 \%$ respectively.

ASD was the second most common CHD (14.9\%) in our study overall as well as in acyanotic lesions followed by PDA (13.1\%). The frequency of ASD has been variable in different studies. Recently a study done at Uganda Heart Institute by Namuyonga $\mathrm{J}$ et $\mathrm{al}^{19}$ showed $9.4 \%$ children had ASD while $22 \%$ children had PDA. Similarly a study in India by Meena AK et $\mathrm{al}^{20}$ showed that ASD was the second most common acyanotic CHD (12.8\%) followed by PDA (8.5\%). Our study is comparable to this study. The relative frequency of AV canal defects, valvular pulmonary stenosis and valvular aortic stenosis is low in out study which matches other studies. ${ }^{21}$ 
In our study tetralogy of Fallot was the commonest cyanotic heart defect and the overall incidence was $10.1 \%$ among congenital cardiac lesions. The incidence of TOF was $8.8 \%$ among total CHD patients noted by Hussain I at $\mathrm{al}^{22}$ in their study while the incidence of TOF among cyanotic CHD was $47.2 \%$. Patra $S$ at al also described $44 \%$ cases of TOF among cyanotic CHD subjects. ${ }^{23}$ In our study the TOF incidence among cyanotic lesions was $37.7 \%$ which correlates with above studies. The described prevalence of TOF among all congenital lesions in our study correlates well with the described prevalence previously. ${ }^{24}$

Transposition of great arteries was the second most common cyanotic heart disease and fifth in the order of frequency of congenital cardiac defects $(7.4 \%)$ in our study. It is the second most prevalent CCHD described but its percentage in our study was quite high as compared to recent data. ${ }^{25}$ This high incidence of TGA in our study could be due to natural selection of patients, limited number of institutes for definite treatment of such patients and more facilities for symptomatic medical treatment before being referred for surgery.

The frequency of some rare cyanotic heart defects was low in our study for example Ebstein anomaly $(0.7 \%)$, truncus arteriosus $(0.6 \%)$, univentricular heart $(0.7 \%)$ and hypo-plastic left heart syndrome $(0.2 \%)$. The study is comparable to Bibi S et al study done in Peshawar ${ }^{26}$ where the recoded incidence of most of such cyanotic lesions was also low. The incidence of such defects is extremely low in our set up because we think that such neonates or infants usually die in neonatal life and if present by natural selection they are late in diagnosis and unable to get treatment in such remote area of the province where even limited neonatology centre are available for care of sick neonates.

\section{Acquired heart diseases (AHD)}

These were found in $13 \%$ of total pediatric cardiac defects which is quite high. Although the acquired heart diseases are not very common in childhood but due to improvement in healthcare and diagnostic facilities the prevalence of such lesions has increased. ${ }^{27}$

The AHD can present at any age. In our study $63 \%$ were between 5 to 12 year of age and $16 \%$ were above 12 year. A study conducted in city of Curitiba, $45 \%$ children were of school age group, $15 \%$ adolescents and $25 \%$ infants with AHD while we have $10 \%$, but the results in terms of age of presentation are almost same. ${ }^{28}$

Rheumatic heart disease is the commonest AHD in our study (55.6\%). The frequency of AHD is variable. Our study has comparable findings to a study conducted in north central Nigeria. ${ }^{29}$ Another study conducted in three centers of Nigeria described that myocarditis/cardiomyopathy are the commonest $\mathrm{AHD}^{30}$ but the data from other developing countries has suggested that the rheumatic heart disease is still the commonest AHD there due to poor socioeconomic conditions. ${ }^{31,32,33}$ In some developed countries Kawasaki disease is the most prevalent AHD than rheumatic heart disease. ${ }^{34}$ We did not have a single case of Kawasaki disease.

Dilated cardiomyopathy (DCMP) is the most common AHD in children age 5 years or below. In our study it was the second commonest acquired heart disease (27.2\%) after rheumatic heart disease, as we have included children up to 18 year of age. Most of the time DCMP is secondary to viral myocarditis. Although to find its cause is beyond the scope of our study but its need of time to study its causes as it is one of the common AHD in children and cause of significant morbidity. ${ }^{35}$

Infective endocarditis was present in $4 \%$ of AHD patients. It is mostly associated with underlying cardiac defect and is one of the important causes of hospitalization in children with congenital heart diseases. $^{36}$

Pulmonary hypertension was mostly associated with acyanotic heart diseases, but $10.2 \%$ of children with AHD also had it and it affects the prognosis of the disease. ${ }^{37}$ 


\section{CONCLUSION}

Congenital heart diseases are more common than acquired cardiac lesions. Infancy is the time of presentation of most of the congenital heart diseases in our setup while acquired heart diseases present at or above 5 year of age. Rheumatic heart disease is still the most common acquired heart disease in our part of the world.

\section{LIMITATIONS}

The study was conducted in the only available facility for children suffering from heart defects in remote area of South Punjab. Many of such children usually do not present at all or present late and due to this the study does not confer the true incidence of such cardiac issues in children but even then our results are still comparable to the available data.

Copyright $\odot 10$ Sep, 2020.

\section{REFERENCES}

1. Mughal AR, Tousif R, Alamgir AR, Jalal A. Pattern of un-operated Grown Up Congenital Heart (GUCH) patients presenting to a Tertiary Care Cardiac Institute of Punjab. Pak J Med Sci 2019; 35(4):10661071. doi: https://doi.org/10.12669/pjms.35.4.878

2. Hoffman Jl. The global burden of congenital heart disease. Cardiovasc j Africa 2013; 24(4):141-5. doi: 10.5830/CVJA-2013-028.

3. Sadiq M, Roshan B, Khan A, Latif F, Bashir I, Sheikh SA. Pattern of pediatric heart diseases in Pakistan. J Coll Physicians Surg Pak 2002; 12(3):149-53.

4. Rizvi SF, Mustafa G, Kundi A, Khan MA. Prevalence of congenital heart disease in rural communities of Pakistan. J Ayub Med Coll Abbottabad 2015; 27(1):1247.

5. Farooqui R, Haroon UF, Niazi A, et al. Congenital heart diseases in neonates. J Rawal Med Coll (JRMC) 2010; 14: $31-2$.

6. George IO, Frank-Briggs Al. Pattern and clinical presentation of congenital heart diseases in PortHarcourt. Nigerian journal of medicine: journal of the National Association of Resident Doctors of Nigeria. 2009; 18(2):211-4.

7. Nordet P. WHO programme for the prevention of rheumatic fever/rheumatic heart disease in 16 developing countries: report from phase I (198690). Bulletin of the World Health Organization 1992; 70(2):213-9.
8. Chelo D, Nguefack F, Menanga AP, et al. Spectrum of heart diseases in children: an echocardiographic study of 1,666 subjects in a pediatric hospital, Yaounde, Cameroon. Cardiovasc Diagn Ther 2016; 6(1):10-19. doi:10.3978/j.issn.2223-3652.2015.11.04

9. Mohammad N, Shaikh S, Memon S, Das H. Spectrum of heart disease in children under 5 years of age at Liaquat University Hospital, Hyderabad, Pakistan. Indian heart J 2014; 66(1):145-9. doi: 10.1016/j. ihj.2013.12.041. Epub 2014 Jan 8.

10. Sadoh WE, Uzodimma CC, Daniels Q. Congenital heart disease in Nigerian children: a multicenter echocardiographic study. World J PediatrCongenit Heart Surg. 2013;4(2):172-176. doi:10.1177/2150135112474026

11. Van derLinde D, Konings EE, Slager MA, et al. Birth prevalence of congenital heart disease worldwide: a systematic review and meta-analysis. J Am Coll Cardiol 2011; 58(21):2241-7. doi: 10.1016/j.jacc.2011.08.025. .

12. Sani MU, Mukhtar-Yola M, Karaye KM. Spectrum of congenital heart disease in a tropical environment: an echocardiography study. J Natl Med Assoc 2007; 99(6):665-9. PMID: 17595936; PMCID: PMC2574369.

13. Ibadin MO, Sadoh WE, Osarogiabon W. Congenital heart diseases at the University of Benin Teaching Hospital. Nigerian Journal of Paediatrics. 2005; 32(2):29-32.

14. Pinto Júnior VC, Branco KM, Cavalcante RC, et al. Epidemiology of congenital heart disease in Brazil. Rev Bras Cir Cardiovasc 2015; 30(2):219-24. doi: 10.5935/1678-9741.20150018

15. Dixit R, Rai SK, Yadav AK, et al. Epidemiology of Congenital Heart Disease in India [published correction appears in Congenit Heart Dis. 2019 Nov;14(6):1214]. Congenit Heart Dis. 2015; 10(5):437446. doi: $10.1111 /$ chd. 12220

16. Adebayo BE, Ogunkunle OO, Omokhodion SI, et al. The spectrum of structural heart defects seen in children at the University College Hospital, Ibadan. Nig J Cardiol 2016; 13:130-5. DOI: 10.4103/01897969.187712

17. Ahmad R, Awan ZA, Bukshi F. A prevalence study of congenital heart disease in NWFP, Pakistan. Pak J Med Sci. 2002; 18: 95-98. [Google Scholar]

18. Rahim F, Younas M, Gandapur AJ, Talat A. Pattern of congenital heart Diseases in children at tertiary care center in Peshawar. Pak J Med Sci. 2003;19(1): 19-22. [Google Scholar] 
19. Namuyonga J, Lubega S, Aliku T, Omagino J, Sable C, Lwabi P. Pattern of congenital heart disease among children presenting to the Uganda Heart Institute, Mulago Hospital: a 7-year review. Afri Health Sci. 2020; 20(2): 745-752. https://doi.org/10.4314/ahs.v20i2.26

20. Meena AK, Agrawal DK, Agrawal R. Spectrum of congenital heart diseases at tertiary-care hospital in north western Rajasthan in India. Int $\mathrm{J}$ Med Sci Public Health 2016; 5:2332-2336. DOI: 10.5455/ ijmsph.2016.20032016477

21. Mukhtar G, Rashid A, Rather $H$, et al. Spectrum of congenital heart disease at Sheri-Kashmir Institute of Medical Sciences. JMS 2019; 22(3):12-15. doi :https://doi.org/10.33883/jms.v22i3.451

22. Hussain I, Zeb S, Irfan M, Ali U. Spectrum of Congenital Cyanotic Heart Disease In KhyberPakhtoonkhwa. Pak Heart J 2015; 48(4): 190-93.

23. Patra S, Rama Sastry UM, Mahimaiha J, et al. Spectrum of cyanotic congenital heart disease diagnosed by echocardiographic evaluation in patients attending paediatric cardiology clinic of a tertiary cardiac care centre. Cardiol Young 2015; 25(5):861-867. doi: $10.1017 /$ S1047951114000882

24. Maury $P$, Sacher F, Rollin A, et al. Ventricular arrhythmias and sudden death in tetralogy of Fallot. Arch Cardiovasc Dis 2017; 110(5): 354-62. https://doi. org/10.1016/j.acvd.2016.12.006

25. Ossa Galvis MM, Bhakta RT, Tarmahomed A, et al. Cyanotic Heart Disease. [Updated 2020 Jul 2]. In: StatPearls [Internet]. Treasure Island (FL): StatPearls Publishing; 2020 Jan-. Available from: https://www.ncbi. nlm.nih.gov/books/NBK500001/

26. Bibi S, Gilani SYH, Bibi S. Spectrum of congenital heart disease in full term neonates. $J$ Ayub Med Coll Abbottabad 2018; 30(1): 67-70. PMID: 29504333

27. Musa NL, Hjortdal V, Zheleva B, et al. The global burden of paediatric heart disease. Cardiol Young 2017; 27(S6):S3-8. Doi: 10.1017/S1047951117002530

28. Miyague Nelson Itiro, Cardoso Silvia Meyer, Meyer Fabrício, et al. Epidemiological study of congenital heart defects in children and adolescents: analysis of 4,538 cases. Arq. Bras. Cardiol. [Internet].2003Mar[cited 2020 July 30]; 80(3):274 278.http://www.scielo.br/scielo.php?script = sci arttext\&pid $=$ S0066 782X2003000300003\&Ing =en. https://doi.org/10.1590/S0066-782X2003000300003
29. Bode-Thomas F, Ige OO, Yilgwan C. Childhood acquired heart diseases in Jos, north central Nigeria. Niger Med J 2013; 54(1): 51-58. doi:10.4103/03001652.108897

30. Wilson SE, Chinyere UC, Queennette D. Childhood acquired heart disease in Nigeria: an echocardiographic study from three centres. Afr Health Sci 2014; 14(3):609-16. doi: 10.4314/ahs. v14i3.16

31. Nkoke C, Menenga A, Boombhi J, et al. A new look at acquired heart diseases in a contemporary subSaharan African pediatric population: the case of Yaoundé, Cameroon. Cardiovasc Diagn Ther 2015; 5(6): 428-34. doi:10.3978/j.issn.2223-3652.2015.08.02

32. Reményi B, Wilson N, Steer $A$, et al. World Heart Federation criteria for echocardiographic diagnosis of rheumatic heart disease--an evidence-based guideline. Nat Rev Cardiol 2012; 9(5): 297-309. doi:10.1038/nrcardio.2012.7.

33. Snider R. The normal echocardiographic examination. In: Snider RA, Ritter SB, Serwer GA. Echocardiography in paediatric heart disease. 2nd edition. United States of America: Walsworth; 1997.

34. Singh S, Vignesh P, Burgner D. The epidemiology of Kawasaki disease: a global update. Arch Dis Child 2015; 100 (11):1084-8. doi:10.1136/ archdischild-2014-307536. Epub 2015 Jun 25

35. Puggia I, Merlo M, Barbati G, et al. Natural history of dilated cardiomyopathy in children. J Am Heart Assoc 2016; 5(7):e003450. doi: 10.1161/JAHA.116.003450)

36. Dixon G, Christov G. Infective endocarditis in children: an update. Curr Opin Infect Dis 2017; 30(3): 257-67. doi: 10.1097/QCO.0000000000000370.

37. Hansmann G. Pulmonary hypertension in infants, children, and young adults. J Am Coll Cardiol 2017; 69(20):2551-69. DOI: 10.1016/j.jacc.2017.03.575 


\begin{tabular}{|c|l|l|l|}
\hline \multicolumn{3}{|c|}{ AUTHORSHIP AND CONTRIBUTION DECLARATION } \\
\hline Sr. \# & \multicolumn{1}{|c|}{ Author(s) Full Name } & \multicolumn{1}{c|}{ Contribution to the paper } & Author(s) Signature \\
\hline 1 & Ahsan Beg & $\begin{array}{l}\text { Principal Investigator, Collected } \\
\text { all the Data, Wrote the } \\
\text { introduction, and Methodology. } \\
\text { Did Data analysis, worte the } \\
\text { results and references. } \\
\text { Wrote the discussion and } \\
\text { abstract }\end{array}$ \\
\hline 3 & Abdul Razzaq Mughal & Nousheen Fatima \\
\hline
\end{tabular}

